\title{
LÚDICA Y LUDOPATÍA
}

\author{
CARLOS BOLIVIAR BONILLA BAQUERO *
}

\section{RESUMEN}

En un escrito de reciente publicación (Ver, Una Aproximación al Concepto de Lúdica, Revista Kinesis $N^{0} 22$ ) se intenta caracterizar la Lúdica, dotándola de un sentido humano más trascendental que desborda la común idea de definirla como simple juego. Al avanzar en la reflexión sobre el particular, aparece ahora la necesidad de diferenciar Lúdica de Ludopatía., diferenciación sobre la cual versa este trabajo.

En la publicación mencionada se propone que la Lúdica sea concebida, en esencia, como una dimensión del desarrollo humano tan importante como la cognitiva, la sexual y la comunicativa, entre otras. Además, se precisa que la Lúdica se refiere a la necesidad que tiene toda persona de sentir emociones placenteras asociadas al vértigo, la incertidumbre, la distracción, la sorpresa o la contemplación gozosa.

También se define allí la Lúdica como una actitud personal frente a la vida, caracterizada por rasgos tales como la creatividad, la espontaneidad, el optimismo y el buen sentido del humor; rasgos que afloran en las interacciones personales cotidianas.
De esta manera se diferencia la Lúdica de sus satisfactores, múltiples casi hasta el infinito: hacer chistes y bromas, ir a paseos, bailar, escuchar música, ver películas, leer, coleccionar, contemplar la naturaleza o el arte, jugar, hacer deporte, cultivar el erotismo, etc.

Al sustentar estas ideas en algunos circulos académicos aparece con frecuencia la pregunta relativa a si también consumir sustancias psicoactivas, conducir en la ciudad un vehículo a máxima velocidad, jugar bingo en los casinos, embriagarse o "picar" la motocicleta en una rueda, por ejemplo, son o no experiencias lúdicas.

Dos investigaciones cualitativas realizadas en 1997, por profesores de la Universidad Surcolombiana', permiten establecer la coincidencia entre el planteamiento teórico sobre el concepto de Lúdica y las opiniones de los propios adolescentes, acerca del tipo de prácticas en cuestión., como se verá más adelante.

Todo parece indicar entonces que la pregunta, antes formulada, debe ser respondida de manera afirmativa. Es lúdico sentir el

Profesor Titular de la Universidad Surcolombiana. Director del Postgrado de Pedagogía de la Expresión Lúdica

1. Garzón Núñez, Abigaíl y Rodríguez, María Elena. La Práctica de Alta Velocitad en Moto y su Significado para los Adolescentes de Neiva. 
vértigo del descenso por la montaña rusa como también lo es adelantar en moto un carro a alta velocidad. Así responde un joven motociclista urbano a las profesoras Núñez y Rodríguez:

"Me gusta sentir el vértigo de la velocidad, la "loquina".Me gusta adelantarmele a los carros por "recocha", o sea, sentir la emoción de ir rápido y adelantar el carro"

Y otro les dice:

"En el momento en que voy en la moto no pienso, si yo pienso,seguro me mato., porque eso es sentir, cuando voy en la moto no pienso en el riesgo".

En consecuencia, ¿Cómo negar el carácter lúdico de esta riesgosa práctica?. Así mismo, si se reconoce que es lúdico para algunos llegar al éxtasis mediante la lectura de la poesía de Neruda o mediante una sinfonía de Beethoven, ¿por qué no reconocer como lúdico el éxtasis que logran otros con sustancias psicoactivas? Peter Laurie cita las palabras de una chica adicta:

"Estuve toda la noche en el Club, tomando estas pildoras cada hora o asi, y nunca me había divertido tanto en la vida, me sentia en la cumbre del mundo,como si pudiera bailar, charlar y reir para siempre, oyendo discos y bebiendo café"

No se puede desconocer la emoción Lúdica existente en la incertidumbre y el azar del juego de bingo, sea éste practicado en la fiesta anual del colegio o en la cotidianidad del casino. ¿Dónde está pués la diferencia entre unas y otras experiencias? ¿Son iguales? Ambas son lúdicas, pero, por supuesto, no son iguales; si se analizan en perspectiva del desarrollo humano y social, y en el marco de la educación como formación.

La diferencia no está en la emocionalidad lúdica que unas y otras prácticas reportan a quienes las ejecutan; todas, se ha dicho ya, propician sensaciones similares de carácter lúdico. La diferencia sustancial reside en el efecto y las consecuencias que ellas implican para la vida de las personas.

Surge la necesidad de acudir a una categoría que permita diferenciar las prácticas lúdicas deseables y convenientes para el desarrollo armónico e integral, de aquellas que lo afectan de modo negativo, con alto riesgo para la salud y la vida misma.

A las primeras puede seguir llamándoseles, simplemente, lúdicas. A las segundas, aquellas que expresan un degeneramiento del sentido lúdico saludable, puede clasificárseles bajo la denominación que identifica esta especie de enfermedad: Ludopatía(s). Autores como Goleman lo exponen asi: "Cuando las emociones son demasiado apagadas crean aburrimiento y distancia, cuando están fuera de control y son demasiado extremas y persistentes, se vuelven patológicas" 3 .

De este modo, la Ludopatía puede concebirse como la resolución de la necesidad lúdica del ser humano, mediante "satisfactores" que ocasionan trastornos de salud, con evidentes consecuencias negativas para la calidad de vida personal, familiar y social. Seudosatisfactores, es la categoría que Max Neef emplea para referirse a este tipo de medios, que pueden ilustrarse todavía más con los ejemplos de quienes pretenden resolver las necesidades de afecto de sus familiares, con regalos costosos y no con un trato tierno, cariñoso, dialógico-compren-

2. Laurie, Peter. Las Drogas. Aspectos médicos psicológicos y sociales. Edit. Alianza del Prado, 1994. Madrid (E) Pag.93.

3. Goleman, Daniel. La Inteligencia Emocional. Javier Vergara Editor, 1996, Buenos Aires (A) Pag.78 


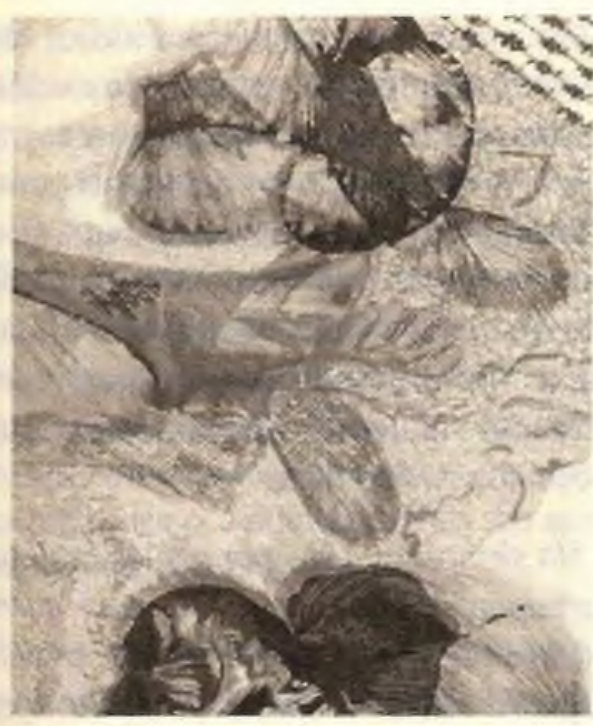

Ilustración: Angélica Maria Martinez

sivo, etc. o también, el caso de quienes aspiran a resolver las necesidades de tipo cognitivo-académico, mediante la "copia" y el aprendizaje mecánico-memorístico, y no a través del esfuerzo constructivo y el aprendizaje significativo.

El Ludópata es un ser que, por razones aún poco claras, sólo encuentra emocionante su vida al ejecutar prácticas de verdadero alto riesgo, hasta caer en la habituación y adicción. La expresión, alto riesgo, que con frecuencia se atribuye a algunos deportes modernos, no parece exacta en esos casos, como sí ocurre en la ludopatía. ¿Cómo equiparar el riesgo del Ciclomontañismo o el Jumping, con el de las sustancias psicoactivas o el motociclismo urbano en estado de embriaguez?.¿Cuántos son los heridos o muertos, en cada caso, después de su práctica en un fin de semana?.

Recuérdese que en las prácticas deportivas se ha previsto al máximo el accidente, mediante el entrenamiento planificado, el mantenimiento de los implementos, la disponibilidad de equipos médicos de urgen- cia, revisión de los escenarios y la exclusividad de los mismos para los deportistas. En las prácticas de los ludópatas no sucede lo mismo y, por el contrario, la emoción se incrementa al no pensar en nada de ésto o, peor aún, yendo en contravía de tales cuidados.

La adicción del ludópata por una determinada práctica, como la camorra en las tribunas del estadio, el juego de azar o la velocidad automotriz, reviste las mismas características de adicciones más comúnes o reconocidas, por ejemplo, en los casos del licor o los fármacos. La ludopatía también conduce a la dependencia compulsiva e incontrolable, de la práctica elegída, al punto de que su interrupción o impedimento de realización produce serias reacciones fisiológicas, emocionales y/o mentales. Al respecto Elías y Dunning citan las palabras de un fanático del fútbol (Hooligan):

"Yo voy a los partidos por una sóla razón: el "aggro". (derivado de aggravatión, significa conducta agresiva y lo que ésta implica: irritar, exasperar, provocar,vejar. Argot caracteristico de las bandas juveniles Inglesas) Es una obsesión, no puedo dejarlo. Disfruto tanto cuando estoy en ello que casi me meo de gusto en los pantalones". ${ }^{4}$

En la Lúdica el individuo decide voluntaria y autónomamente cuándo realizar la actividad, así como también cuando finalizarla. En la ludopatía, la práctica termina dominando al sujeto quien ya no puede decidir por si mismo. De qué otra manera podría explicarse un comportamiento como el anterior o como el siguiente, expresado por uno de los jóvenes motociclistas investigado por Núñez y Rodríguez:

"Yo me he accidentado unas 20 veces en la moto, mi mamá me dice que ya no me mato

4. Elías Norbert y Dunning Eric. Deporte y Ocio en el proceso de Civilización. Edit. Fondo de Cultura Económica . Madrid (E) 1992, pag. 296. 
en ella. De éstas, cinco las he tenido porque he estado tomando, porque no coordino los sentidos. Me he abierto la cara, los brazos y tengo mis dos piernas quebradas"

Con toda razón Montaigne, hablando de la embriaguez, dice que:

"El peor estado del hombre es aquel en el que pierde el conocimiento y el dominio de si"s.

Debe advertirse que no todo aquel que experimenta una vez o ejecuta de forma eventual una de éstas acciones de alto riesgo es, automáticamente, un ludópata. Se reserva esta categoría para aquellas personas que dependen de manera compulsiva de la práctica seleccionada, al extremo de que, en procura de la emoción se llega con facilidad al accidente, la calamidad doméstica, la riña o la enfermedad y, no obstante, la experiencia se repite una y otra vez. Se sabe que un apostador puede llegar a perder gradualmente los bienes familiares pero repetirá la apuesta aún en la miseria. Igual le ocurre al camorrista del fútbol, puede ser golpeado y hasta detenido, innumerables veces, sin por ello evitar la diversión pendenciera.

Para aclarar todavía más la diferenciación entre Lúdica y Ludopatía, resulta conveniente seguir insistiendo en la similitud de esta dimensión y necesidad humana con otras de igual importancia como la sexual. En la última también puede ocurrir que la persona enriquezca su desarrollo humano, mediante la consecución de una pareja con quien compartir el amor, el erotismo y el mismo sexo. Pero, en casos de degeneración de la sexualidad, pudiera llegarse a resolver esta necesidad únicamente con animales (Zoofilia) o con los objetos y prendas de otra persona (Fetichismo).
Si se revisa la actual cultura lúdica de la sociedad Colombiana, es decir, los valores, actitudes, prácticas y creencias en torno a qué es la diversión y lo emocionante, puede constatarse que, por desgracia, existe una tendencia fuerte a la ludopatía, particularmente entre los jóvenes escolares. En la investigación sobre Cultura Corporal, reseñada atrás, el siguiente tipo de comentarios aparece con insistencia:

"No siempre se bebe porque los amigos to presionan a uno, sino porque uno quiere y siente que la garganta se lo pide, porque el aguardiente es lo que lo prende a uno, lo que lo hace más feliz, lo hace moverse, pierde uno la pena, se destapa uno". ${ }^{6}$

"Yo para poder prenderme, para poder tomar y estar bien, no me prendo facil, con dos cervezas no. Soy durita, digamóslo así, para estar bien borracha tengo que revolver, tomar aguardiente, tengo que tomar cerveza, tomar brandy, todo eso, pero en un tiempo corto y harto y revuelto".

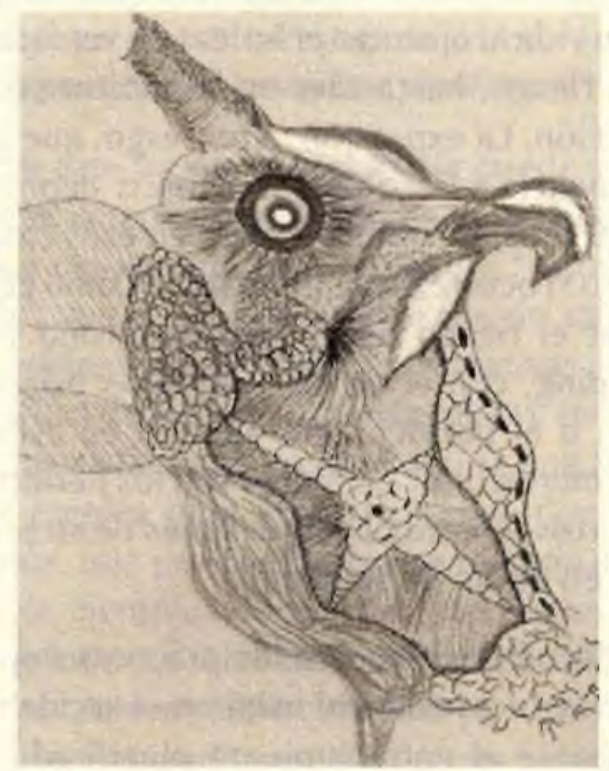

Ilustración: Maribel Castro Calderon

5. Montaigne , M. De la Embriaguez, en: Ensayos Tomo II Edit. Aitaya. Barcelona (E) 1995, Pag.20.

6. Bonilla Baquero, Carlos Bolívar. Interpretaciones sobre la Cultura Corporal de los Adolescentes Escolares. 
Es evidente que el ambiente cultural juega aquí un importante papel y, sin embargo, no puede ser considerado suficiente para explicar los comportamientos ludópatas. Aunque en este ensayo no se aborda el problema de la causalidad, conviene al menos esbozar que existe también una explicación de tipo bioquímico, según la cual, las personas poseen diferentes comportamientos emocionales derivados de particulares balances o desbalances en sus neurotrasmi-sores cerebrales.

Según el Dr. Steward Montogomery, del Imperial College Scholl of Medicine, de Inglaterra, estas sustancias:

"Tienen que ver con el ánimo pero desde diferentes frentes. La serotonina, en el impulso e irritabilidad, la dopamina en la vitalidad y la noradrenalina, con la energía, la motivación"?

No obstante, el autor de este escrito tampoco cree que, por si sola, la explicación bioquímica permita comprender el orígen de la ludopatía, inclinándose a favor de una postura interactiva; entre tipos de personalidades (neurotransmisores) y contextos socioculturales.

Parece más razonable creer que si las personas poseen ciertas disposiciones emocionales intrínsecas, en su interacción con los ambientes familiares y escolares podrán desarrollar estas potencialidades interiores, hasta llegar a convertirlas en determinadas prácticas sociales. Lo que equivale a decir que los contextos socioculturales pueden bloquear un talento o estimularlo. Así mismo pueden evitar una inclinación "natural" a la ludopatía o a acentuarla.

Por esta razón, por ejemplo, personalidades con tendencia a la timidez e inactivi- dad pueden caer con facilidad en el consumo del licor que promueven los medios. No sólo porque los medios inciten sino, además, porque el licor posee en verdad un efecto desinhibidor.

De lo anterior se deduce que la importancia de los ambientes de socialización, especialmente familiares y escolares, es decisiva para propiciar o no experiencias y orientaciones que beneficien la formación de una cultura lúdica o ludópata.

Si el hogar y la institución escolar no ofrecen a los tímidos e inactivos sanas alternativas de superación y diversión, la publicidad logrará su cometido y el consumo de alcohol será la opción elegida "para divertirse", "para estar bien", "para sentirse diferente", como lo expresan los jóvenes estudiantes.

En el ámbito escolar, la Educación Física cobra un enorme significado para la orientación juvenil hacia la internalización de una cultura lúdica que beneficie el desarrollo integral de los educandos. Para que lo anterior sea posible es necesario que la clase y la actitud del docente sean lúdicas: atractivas, dinámicas, interesantes y muy divertidas. En esta clase no se puede repetir el esquema rígido, pasivo y autoritario de las asignaturas de aula.

Si la clase de Educación Física no consulta por los intereses lúdicos de los estudiantes, para abrir un amplio abanico de alternativas: bailes modernos, juegos, paseos, caminatas, expresión artístico-corporal, aeróbicos, etc., está limitando sus posibilidades de orientación pedagógica y, al repetir el esquema antilúdico de las otras materias, empuja, sin querer, a la ludopatía.

Es obvio que la misma responsabilidad recae en la familia. Si los niños y jóvenes no

7. En Artículo: Más que Angustia Existencial. De Marisol Ortega Guerrero. El Tiempo, domingo 21 de junio de 1998 P.I.C. Sección Salud. 
ven en ella espacios ni momentos lúdicos $y$, a cambio, sólo viven ambientes de tipo autoritario, de soledad e incomunicación afectiva, tienden a buscarle sentido emocional a sus vidas en otros escenarios, no siempre convenientes a su sana formación.

Es lo que sugieren algunos Etnógrafos Españoles cuando plantean:

"Al lado (o frente) de las comunidades racionales, las de espíritu Empresarial, por ejemplo, se van (o) poniendo las comunidades emocionales, es decir, aquellas que se fundamentan en la comunión de emociones intensas, a veces efimeras y sujetas a la moda, pero siempre dotadas de un talante agregativo. Están formadas por individuos que se reúnen -y atavían de forma parecidapara compartir una actividad y una actitud que generan sensaciones fuertes $y$ confieren sentido a una existencia donde, en el fondo, hay falta de contacto y contagio emocional"s

Si la escuela y la familia insisten en sus proyectos Educativos como proyectos laborales-Empresariales y no como un proyectos lúdicos-culturales, seguirán fallando al promover el mensaje mediante el cual los jóvenes aprenden que dentro de ellas se encuentra todo lo aburrido y detestable, y que, en su exterior, habrá que buscar lo emocionante y divertido, al precio que sea necesario. Precio que la comunidad Colombiana está pagando muy caro.

Para terminar, no se pueden soslayar las responsabilidades del Estado y de la sociedad consumista, manipulada por los intereses lucrativos de quienes tienen el poder político y económico, en cuanto al fomento de una cultura ludópata. Cultura de la cual derivan multimillonarias ganancias y poderosos controles ideológicos.

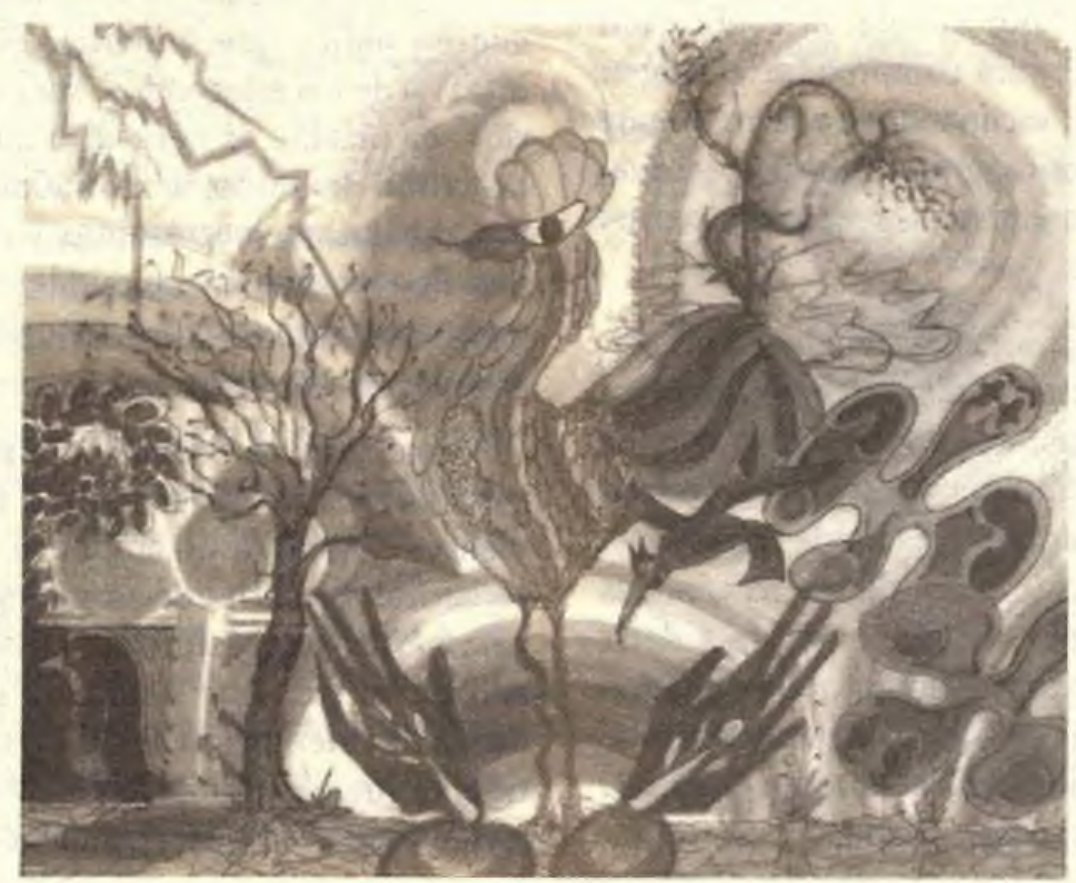

llustración: Efren Mosquera Villarreal

8. Oriol Costa Pere y otros. Tribus urbanas. Edit. Paidos. Barcelona 1996. Pag.54 